\title{
Desafios da regulamentação ante a dinâmica concorrencial bancária: uma perspectiva pós-keynesiana ${ }^{1}$
}

\author{
Maria Cristina Penido de Freitas ${ }^{2}$
}

\begin{abstract}
Resumo
O objetivo desse artigo é discutir, a partir do referencial pós-keynesiano, os desafios da regulamentação prudencial ante a dinâmica concorrencial dos bancos. Submetidos à lógica implacável da valorização da riqueza em um mundo de incerteza e irreversibilidade, essas instituições-chave do sistema de pagamento e crédito buscam contornar os limites fixados pela regulamentação e tendem a assumir riscos que ampliam sua instabilidade intrínseca. Para evitar a ocorrência de situações que os obrigue a atuar como prestamista em última instância, os bancos centrais procuram limitar o espaço da concorrência bancária mediante a regulamentação prudencial. Porém, continuamente os bancos procuram desenvolver novas práticas e instrumentos que lhes permite contornar as exigências regulatórias. Existe assim uma tensão contínua entre o processo competitivo inovador dos bancos (e de outras instituições financeiras) e a necessidade de aperfeiçoamento da regulamentação. Esse desafio tornou-se ainda maior no contexto atual de globalização e integração dos mercados e de notável avanço tecnológico que permite o desenvolvimento de novos produtos financeiros a partir de sofisticadas e complexas técnicas de engenharia financeira, cujos riscos subjacentes são de difícil avaliação.
\end{abstract}

Palavras-chave: Regulamentação bancária; Concorrência bancária; Inovação financeira; Prestamista em última instância; Teoria pós-keynesiana.

\section{Abstract \\ The challenges of prudential regulation for the dynamics of bank competition: a Post Keynesian perspective}

The purpose of this article is to discuss from a Post Keynesian perspective the challenges of prudential regulation for the dynamics of bank competition. These key institutions of the payment and credit system are submitted to the irresistible logic of increased wealth in a world of uncertainty and irreversibility. In this context, they tend to assume risks that increase their inherent instability. Central banks, seeking to avoid becoming the lender of last resort, have attempted to limit the space for bank competition through prudential regulation. However, banks have continued to develop new practices and instruments allowing them to circumvent such regulatory requirements. A continuous tension thus emerges between the innovative competitive process of the banks and the need to perfect regulation. This challenge has grown further in the current context of globalization and market integration and also of notable technological advances that allow for the development of new financial products based on sophisticated and complex financial engineering, whose side effects are difficult to predict.

(1) Trabalho recebido em abril de 2008 e aprovado em maio de 2009. A autora agradece a Daniela Magalhães Prates pela leitura atenta, bem como ao parecerista anônimo, eximindo-os das falhas e omissões remanescentes.

(2) Doutora em Economia pela Université de Paris 13. São Paulo, SP, Brasil. E-mail: crispenido@uol.com.br. 
Maria Cristina Penido de Freitas

Key words: Banking regulation; Banking competition; Financial innovations; Lender of last resort; Post Keynesian economics.

JEL B5, G21, G28.

\section{Introdução}

$\mathrm{Na}$ economia capitalista moderna, a moeda faz parte de um arranjo institucional complexo, que inclui o banco central, o sistema bancário e um conjunto de regras que governam o "jogo econômico". Nesta economia, a moeda que está na base de todas as transações econômicas relevantes é uma moeda de crédito de emissão privada. Como parte integrante de um sistema institucional articulado, centralizado e organizado em torno de um banco central, os bancos são os únicos agentes que combinam a gestão dos meios de pagamentos - títulos de dívida emitidos contra eles mesmos - e a gestão do capital de empréstimo.

Embora tenham uma natureza particular e específica, os bancos são igualmente empresas inovadoras e dinâmicas em busca da ampliação dos lucros, que podem conduzir à assunção excessiva de riscos e à eclosão de uma crise financeira, com graves consequências para a atividade econômica em seu conjunto. Assim, de um lado, essas instituições são agentes econômicos que estão submetidos à lógica implacável da valorização da riqueza em um mundo de incerteza e irreversibilidade; de outro lado, por ocuparem um lugar central no processo de criação monetária na economia capitalista moderna, estão sujeitas ao controle e regulação estatal, que lhe circunscreve o espaço concorrencial.

$\mathrm{Na}$ lógica conflitante que opõe a busca de valorização da riqueza pelos bancos e a natureza de "bem público" da função monetária - que essas instituições privadas com fins lucrativos desempenham na economia capitalista - reside o traço distintivo da concorrência bancária. O espaço e as formas da concorrência apresentam a particularidade de serem essencialmente circunscritas aos limites fixados pela regulamentação, os quais variam de acordo com a estrutura institucional e jurídica existente em cada país. Porém, esses limites não são imutáveis; ao contrário, evoluem com o desenvolvimento da economia. Pois os bancos reagem às modificações no ambiente macroeconômico, regulatório e competitivo no qual atuam, ao mesmo tempo em que agem ativamente sobre as transformações que são aí produzidas.

O objetivo desse artigo é discutir os desafios que a dinâmica concorrencial bancária impõe para a atividade de regulamentação. Tendo como referencial teórico as formulações de Keynes no Tratado da Moeda e em escritos posteriores, as contribuições de autores da corrente pós-keynesiana, em particular Victoria Chick e Hyman Minsky, dentre outros, o presente artigo introduz no debate a noção de concorrência como processo, a qual, em razão da natureza particular dos bancos, assume contornos específicos na atividade bancária. Dentro desse 
propósito, discute-se na primeira seção a dupla função dos bancos na economia capitalista e a racionalidade da regulamentação bancária. Em seguida, na segunda seção, analisam-se os desafios enfrentados pela regulamentação na definição do espaço da concorrência bancária. Finalmente, na terceira seção, apresentam-se as considerações finais.

\section{A natureza particular dos bancos na economia capitalista e a racionalidade da regulamentação bancária}

$\mathrm{Na}$ economia capitalista moderna, na qual a moeda é uma moeda de crédito, os bancos desempenham um duplo papel, essencial e complexo, na dinâmica da acumulação do capital. Os bancos executam conjuntamente o papel de criadores de moeda, concedendo crédito, e de intermediários financeiros, atuando como elo entre a esfera da circulação financeira e a esfera da circulação produtiva. Estas duas funções distintas, mas estreitamente interligadas, conferem aos bancos um caráter especial frente às demais instituições financeiras.

Tais funções específicas, que os bancos desempenham em uma economia monetária de produção como a economia capitalista, são consequências da evolução histórica, legal e institucional de cada nação (Minsky, 1986, p. 222). Foi esta evolução que determinou quais instituições financeiras poderiam se comportar como bancos. Um conjunto de regras restringe as instituições que criam moeda pela expansão do crédito, de modo a garantir a credibilidade do sistema monetário. $\mathrm{Na}$ ausência da regulamentação, instituições financeiras não-monetárias poderiam equivaler-se às instituições bancárias.

Os bancos têm o poder, por excelência, de monetizar (no sentido estrito do termo) as obrigações primárias emitidas pelos devedores bancários no momento da concessão do crédito, porque os depósitos à vista, enquanto reconhecimentos de dívida emitidos pelos bancos contra si próprios, são utilizados como meio de pagamento para a maior parte das transações econômicas. Porém, um banco individual só pode criar moeda enquanto parte integrante de um sistema de pagamento hierarquizado, centralizado e organizado em torno do banco central. Como guardião da convenção monetária, é o banco central que fornece o meio de liquidação das posições interbancárias líquidas. Em outras palavras, a moeda bancária nasce como moeda privada, cuja validação social é fornecida pelo Estado através do banco central que garante a conversão das moedas bancárias privadas em moeda central. É a existência do banco central que permite que os ativos emitidos pelos bancos (os depósitos à vista) sejam substitutos perfeitos da moeda legal, ou seja, a moeda de curso forçado que é a unidade de conta e meio de pagamento último de todos os contratos econômicos relevantes. 
Ao conceder crédito, os bancos adquirem dívidas emitidas pelos agentes econômicos que, apostando na rentabilidade futura de suas riquezas presentes, solicitam um pré-financiamento de suas atividades. Ao agir assim, os bancos antecipam a validação social das decisões empresariais de produção e de investimentos, colocando à disposição destes a liquidez recém-criada para a viabilização de planos de investimentos e de estratégias de apropriação da nova riqueza. Mediante a concessão de crédito, os bancos permitem a instalação da capacidade produtiva e a expansão da produção a uma taxa que seria difícil imaginar em um mundo de moeda-mercadoria (Davidson, 1978, p. 307). ${ }^{3}$

A criação da moeda bancária permite aos investidores obter um comando imediato sobre os recursos necessários à concretização dos seus planos, mesmo se os poupadores recusarem a lhes ceder o poder de compra potencial, ou seja, a liquidez já existente. Assim, "os bancos não se dedicam somente em alocar fundos já existentes, mas, ao contrário, são participantes-chaves do processo de criação da riqueza" (Studart, 1993, p. 263).

Todavia, na economia capitalista não há nada que garanta, frente ao futuro incerto, o sucesso das apostas efetuadas pelos agentes econômicos. ${ }^{4} \mathrm{Se}$ os bancos acomodam os prejuízos, concedendo novos empréstimos, podem contribuir para o surgimento de pressões inflacionárias na economia, que se persistirem por muito tempo poderão redundar na erosão contínua da confiança na moeda enquanto poder de compra geral. A erosão da confiança na moeda poderá, como destaca Carvalho (1993), conduzir à destruição dos fundamentos monetários sobre os quais repousa a ordem econômica. Por esta razão, nem todas as transações efetuadas pelos bancos devem ser validadas pelo banco central.

Os bancos estão submetidos à incerteza como todos os demais agentes econômicos capitalistas, e por isso também possuem preferências pela liquidez que refletem suas expectativas e considerações sobre o ciclo dos negócios. Assim, é possível que, em determinadas circunstâncias, racionem crédito, contribuindo para a diminuição do ritmo de crescimento. Igualmente, podem financiar a especulação com títulos representativos da riqueza passada, privilegiando a circulação financeira em detrimento da circulação industrial, pois o crédito bancário pode ser criado para financiar tanto a compra de ativos financeiros como a ampliação dos bens de investimentos ou ativos de capital.

(3) No que se refere ao financiamento dos investimentos é preciso distinguir entre o financiamento temporário (crédito bancário) e o financiamento permanente (financiamento de consolidação dos investimentos). No primeiro caso, os bancos enquanto criadores de moeda colocam a liquidez recém-criada à disposição dos empresários, enquanto no segundo caso, os bancos e demais intermediários financeiros fornecem o funding de longo prazo aos projetos concluídos, utilizando a poupança financeira criada no processo de investimento.

(4) Excelente síntese dos fundamentos da interpretação pós-keynesiana da economia capitalista é apresentada por Carvalho (1989 e 1992). 
Como intermediários financeiros, os bancos participam da criação do funding necessário para consolidação dos investimentos produtivos, fonte de criação da riqueza material da economia capitalista. Com tal, realizam também a gestão das modificações patrimoniais associadas à distribuição da riqueza nova, criada no processo de acumulação de capital, essencial para o funcionamento menos disruptivo da economia. Ainda como intermediários financeiros, os bancos realizam a transferência de poder de compra, e, portanto, de direitos sobre a riqueza entre os poupadores (rentistas) e os devedores. Porém, esta transferência é indireta, na medida em que entre a propriedade formal da riqueza real e os detentores legítimos da riqueza se interpõem ativos financeiros que representam um direito expresso em termos monetários.

Pela ação dos bancos como intermediários, a distribuição dos direitos sobre a riqueza social não se traduz em transferências constantes da propriedade real. Mas se os bancos não podem (ou se recusam) a acomodar uma nova distribuição de direitos da riqueza em virtude de uma modificação súbita na forma de avaliação da riqueza na economia (como ocorreu, por exemplo, em 1929), os diretos acumulados sobre a riqueza podem não ser exercidos senão mediante rearranjo geral das fortunas privadas e modificações importantes na propriedade real do capital (Keynes, 1931, p. 157).

Em resumo, os bancos têm a capacidade de modificar as condições de liquidez da economia, agindo conjuntamente como criadores de moeda e como intermediários financeiros. Esta característica confere a estas instituições uma posição-chave nos sistemas monetário e financeiro das economias modernas e permite diferenciar os bancos das instituições financeiras não-bancárias que exercem apenas a função de intermediação. As transformações institucionais das últimas três décadas e, em particular, o processo de securitização não alteraram esse caráter singular e essencial da atividade bancária. Os bancos permanecem como as únicas instituições privadas capazes de criar moeda e liquidez, dado que suas obrigações são conversíveis à vista e ao par na moeda legal de curso forçado.

Historicamente, porém, os bancos não executaram sempre essas duas funções conjuntamente. Como destaca Keynes em Treatise on money, quando a moeda era uma moeda-mercadoria, os bancos não agiam senão como intermediários. Nessa época não havia nenhuma conexão estrita entre a oferta de moeda e um tipo particular de crédito. Com o desenvolvimento da moeda bancária associada à constituição de um sistema bancário como uma organização institucional articulada, integrada e hierarquizada, os bancos combinaram as funções de fornecedores de moeda e de liquidez e de intermediação da poupança financeira (Keynes, 1930, p. 191-192). Na terminologia adotada no Tratado, Keynes associa a função bancária de criação da moeda aos depósitos à vista criados em contrapartida à concessão de crédito, enquanto a função de 
intermediação é associada aos depósitos que os bancos recebem dos agentes econômicos e que representa a moeda de crédito previamente criada por outro banco (criação passiva). Mas, ressalta que, se no passado era fácil distinguir entre estes dois tipos de depósitos, desde a metade do século XIX isto já não era mais possível. $^{5}$

Compatível com as proposições teóricas de Keynes, a tipologia elaborada por Victoria Chick (1986 e 1988) para a análise da evolução histórica do sistema bancário inglês nos mostra que, na década de 1970, os bancos começam a administrar ativamente as suas obrigações (liability management). Até esta etapa, que corresponde ao quinto estágio, todos os ajustamentos eram efetuados no lado dos ativos. Administrando também o lado das obrigações, os bancos definem individualmente uma taxa de crescimento para suas aplicações e em seguida ajustam seus compromissos. Os depósitos deixam de ser consequência passiva da política de crédito das instituições bancárias. Os bancos procuram ativamente atrair e conservar os depósitos de poupança financeira que estavam mantidos em outras instituições financeiras.

No caso inglês, o liability management desenvolveu-se sob égide das instituições de regulamentação que concederam aos bancos maior liberdade de ação, em contrapartida ao abandono de práticas de conluio na fixação das taxas de juros dos empréstimos e dos depósitos (Chick, 1986, p. 117). Neste contexto, os bancos passaram a concorrer abertamente pela captação da poupança financeira dos agentes econômicos aplicada sob a forma de instrumentos financeiros emitidos pelas empresas, pelo governo e por outras instituições financeiras. ${ }^{6}$ Nesse estágio, a preocupação das autoridades de regulamentação desloca-se das condições de liquidez para o controle das condições de solvência e adequação de fundos próprios das instituições bancárias.

Nos Estados Unidos, a transição do sistema bancário para o correspondente quinto estágio da tipologia proposta por Chick ocorreu em meados dos anos 50, com o desenvolvimento do mercado de reservas bancárias, a partir das trocas pelos bancos de grandes volumes de recursos que representam excedentes das reservas obrigatórias mantidas junto ao Banco da Reserva Federal. ${ }^{7}$ Um dos primeiros autores a sublinhar o caráter inovador e dinâmico da atividade

(5) Cabe ressaltar que estas reflexões de Keynes aplicavam-se à realidade institucional da Inglaterra. Ele próprio advertia que, na época da elaboração do Tratado, esta distinção ainda era válida em vários países.

(6) $\mathrm{O}$ fato da concorrência via preços não ser permitida na Inglaterra não significava, contudo, que os bancos não competissem. A concorrência por preço é apenas uma forma de concorrência dentre outras e sua adoção, no caso da atividade bancária, pode contribuir para a fragilidade financeira destas instituições, como ilustram as crises do sistema bancário inglês nos anos 1970 e das instituições de depósitos norte-americanas no início dos anos 1980.

(7) A aplicação da tipologia desenvolvida por Victoria Chick ao caso dos Estados Unidos foi realizada por Niggle (1990). 
bancária, Minsky destacou que este desenvolvimento marcou o início de uma modificação profunda das estratégias bancárias nos Estados Unidos. ${ }^{8}$ Com a criação desse novo mercado e o desenvolvimento posterior de novos instrumentos financeiros e a captação de recursos no Euromercado, os bancos americanos começaram a administrar ativamente suas obrigações (Minsky, 1984).

A prática do liability management transformou radicalmente a natureza da atividade bancária. As inovações financeiras associadas ao liability management conferiram um poder liberatório aos passivos das instituições bancárias, ao mesmo tempo em que facilitou o acesso dos devedores aos recursos do sistema financeiro. Mas, se por um lado, os novos instrumentos liberaram os bancos da necessidade de manter reservas secundárias (não-compulsórias) como proteção contra iliquidez, por outro lado, a maior confiança dos bancos nas técnicas e instrumentos de gestão, mais do que na propriedade de ativos líquidos, contribuiu para ampliar de modo considerável o nível de risco da atividade bancária. Como financiam seus ativos de prazos mais longos mediante fundos de curto prazo à taxa de mercado, a inversão da curva de taxa de juros nos momentos de contração do crédito tende a diminuir os lucros dos bancos.

Mediante a administração ativa de suas obrigações, os bancos demonstraram desejo e capacidade de captar fundos mediante a oferta de um amplo leque de taxa de juros. Demonstraram, igualmente, que se desejam ampliar os empréstimos são capazes de encontrar ou de inventar novas oportunidades, mesmo em momentos de retração da atividade econômica (Chick, 1992, p. 202). As estratégias dos bancos para penetrar novos mercados, como foram os casos do mercado internacional de crédito nos anos 1970 e do mercado de derivativos no final dos anos 80, ilustram as ações dinâmicas destas instituições.

O sexto estágio no desenvolvimento bancário é caracterizado pelo processo de securitização dos créditos, mediante o qual os bancos procuram reduzir o risco de iliquidez inerente à atividade bancária (Chick, 1988, p. 7 e 15). Para reduzir o risco associado à transformação de prazos de suas obrigações de curto prazo em aplicações com prazos de vencimento mais longos, os bancos passam a privilegiar a aquisição de ativos negociáveis, cujo valor de mercado flutua em resposta às oscilações nas taxas de juros. Detendo ativos negociáveis -e às vezes mais rentáveis que os títulos públicos -, os bancos tornam-se menos vulneráveis frente às contrações abruptas da liquidez e, por consequência, menos dependentes do suporte do banco central enquanto prestamista em última instância. Essa etapa iniciada no caso inglês e norte-americano no final da década de 1980 caracteriza-se também pela proliferação das transações não-registradas

(8) Minsky analisou o desenvolvimento do mercado de fundos federais em um artigo publicado originalmente em 1957 no Quarterly Journal of Economy e reimpresso em 1982. 
nos balanços (off-balance-sheet), as quais, no primeiro momento, forneceram aos bancos meios de escapar das diretivas regulatórias relativas ao nível e à qualidade do capital próprio do Acordo de Basileia de 1988. ${ }^{9}$ Quando as brechas deixadas pelo Acordo de Basileia foram fechadas e a regulamentação bancária passou a incluir no requerimento de capital mínimo algumas das operações não-registradas no balanço, os bancos intensificaram a criação de empresas de propósito especial ou veículos especiais de investimento (conhecidos como SIV, na sigla em inglês para Structured Investment Vehicle). Para reduzir exigências de capital e liberar recursos para novos negócios, os bancos transferem parte de suas carteiras de crédito para esses veículos, em geral localizados em paraísos fiscais.

Do exame da evolução institucional do sistema bancário, pode-se concluir que os bancos não são nem máquinas criadoras de moeda que funcionam passivamente sob o comando da autoridade monetária, nem simples intermediários financeiros entre os devedores e os credores finais, como preconizam os teóricos do mainstream. Ao contrário, como mostra Freitas (1997 a e b), os bancos são instituições empresariais submetidas à lógica de valorização do capital e, por consequência, à lógica da concorrência como todos os outros tipos de empresas capitalistas. Isso significa que não respondem passivamente às preferências dos demais agentes e, de outro lado, que estão em concorrência entre elas e com outras instituições financeiras para a obtenção do poder de mercado e de maiores lucros nos diferentes mercados financeiros, seja doméstico, seja internacional.

Os bancos estão sob pressão contínua em busca de inovação a fim de aumentar seus lucros. Esses são obtidos, seja mediante o diferencial de taxa de juros entre os empréstimos e os recursos captados, seja mediante as comissões obtidas pela concessão de linhas de crédito, aceites bancários, transações com divisas, cobranças, gestão de fortunas privadas e outros serviços financeiros múltiplos que oferecem.

Mas, os bancos não são empresas exatamente como as outras. De fato, como mencionado no início dessa seção, são os únicos agentes econômicos que, conjuntamente, criam moeda e servem de vínculo entre a circulação industrial e

(9) O Acordo de Basileia de 1988, agora conhecido como Basileia I, previa a harmonização internacional das regulamentações relativas à adequação de capital dos bancos internacionais. Seus principais objetivos eram promover a higidez dos bancos, e assim fortalecer a estabilidade do sistema financeiro internacional e reduzir uma fonte desigualdade competitiva entre os bancos internacionais, já que instituições americanas eram obrigadas a manter níveis de capital muito mais elevado que seus competidores internacionais, em particular, os bancos japoneses. O Comitê da Basileia propunha que o capital mínimo exigido dos bancos refletisse os riscos que esses efetivamente assumem para que possam absorver perdas potenciais, e assim fixou o capital mínimo em $8 \%$ dos ativos ponderados pelos riscos. Originalmente, apenas os riscos de crédito entravam no cálculo do capital mínimo, mas, uma emenda no Acordo aprovada em 1996 (e que entrou em vigor em 1996) introduziu a exigência de cobertura dos riscos de mercados, que se refere à flutuação nos preços dos ativos negociáveis mantidos em carteira pelas instituições bancárias. 
financeira. Eles são também empresas especiais por diversas outras razões. Em primeiro lugar, o métier bancário é por excelência instável e a origem da instabilidade provém da própria natureza da atividade bancária. Como ressalta Minsky (1986, p. 249-250),

os bancos são mercadores de dívida, especializados no financiamento de curto prazo das empresas, dos governos e das famílias. Para obter e ampliar seus ganhos, os bancos fazem o comércio das dívidas, transformando os prazos de vencimento, assumindo riscos e incentivando seus clientes a utilizar os seus serviços.

Em segundo lugar, não existem limitações físicas, tais como custos tangíveis e limites de capacidade, que os impeçam de oferecer seu "produto" principal, a moeda e o crédito. Por essa razão, os bancos têm a tendência a conceder mais crédito do que seria prudente fazê-lo nos momentos de expansão da economia, subestimando os riscos.

$\mathrm{Na}$ criação de novos instrumentos financeiros reside uma terceira diferença importante em relação à indústria. Os bancos não incorrem em despesas de grande magnitude para o desenvolvimento de novos instrumentos, que podem ser rapidamente oferecidos ao público. Não existe registro de patente para os novos ativos financeiros, permitindo que os demais concorrentes possam rapidamente imitar o banco inovador. Assim, os ganhos decorrentes da inovação são mais temporários, porém servem como estímulo à busca contínua de novos produtos e serviços. E os bancos, sobretudo aqueles dos países anglo-saxões onde vigora sistema jurídico de direito comum - no qual tudo o que não é explicitamente proibido é permitido - têm sido pródigos em desenvolver novos produtos e práticas que lhes permitem gerir de forma ativa os seus balanços, de forma a ampliar seus ganhos.

A natureza dos lucros bancários também difere da natureza dos lucros das empresas industriais. Como o setor bancário tem o poder de determinar as condições de liquidez da economia, ele regula a taxa de juros. Por essa razão, não existem "limites naturais" para a taxa de juros. Desse modo, os bancos podem facilitar ou dificultar as condições de funcionamento do processo produtivo que demanda recursos financeiros. Os bancos e seus clientes (as empresas industriais e comerciais) mantêm uma relação dialética especial de conflito e de interdependência. Todavia, o lucro dos bancos não deriva somente do diferencial de juros das suas atividades tradicionais de empréstimo e captação de recursos. Essas instituições oferecem diversos serviços pelos quais recebem comissões e honorários. Além, é claro, dos ganhos de capital de natureza essencialmente especulativa.

Os bancos desempenham, assim, um duplo papel ao mesmo tempo dinâmico e desestabilizador. De um lado, ocupam um lugar central no processo de criação da moeda e da liquidez na economia. De outro, são agentes econômicos 
ativos submetidos à lógica de valorização da riqueza em um mundo de incerteza e de irreversibilidade. A distinção desta dupla dimensão dos bancos é fundamental para a compreensão da instabilidade financeira e a dinâmica cíclica da acumulação.

Esse papel dual das instituições bancárias justifica o controle estatal, o qual é exercido normalmente em duas dimensões. A primeira dimensão, macroeconômica, refere-se à autonomia relativa do sistema bancário privado em criar moeda e em modificar as condições globais de liquidez da economia. A segunda dimensão, microeconômica, diz respeito às atividades das instituições individuais, que podem afetar e ameaçar a segurança do conjunto do sistema bancário, e por consequência do sistema de pagamentos.

A lógica de valorização do capital subjacente ao comportamento dos bancos pode conduzir à eclosão de uma crise financeira, com graves implicações para a atividade econômica em seu conjunto. Assim, considerando a posição única que os bancos ocupam no sistema monetário e de crédito, suas atividades são e precisam ser estritamente regulamentadas.

\section{Dinâmica concorrencial e regulamentação prudencial}

Na busca incessante da valorização da riqueza, os bancos tomam decisões e adotam estratégias cujos resultados incertos podem implicar em falência. $\mathrm{O}$ problema é que, dado o lugar que ocupam na economia como criadores dos meios de pagamentos, a falência de um banco individual pode comprometer a estabilidade do sistema monetário e financeiro em seu conjunto. Através do sistema de pagamentos, a crise financeira pode se generalizar, afetando outros setores da economia. O poder de criação monetária que os bancos possuem na economia capitalista moderna está fundado, como já mencionado, em uma organização institucional particular que é o vasto sistema de pagamento hierarquizado e organizado em torno de um banco central, responsável pela emissão do meio de pagamento último. Os bancos, por estarem no centro desse sistema, possuem um acesso especial à moeda central; e, por essa mesma razão, são submetidos ao controle estatal.

A regulamentação específica da atividade bancária diz respeito à autonomia relativa do sistema bancário de criar moeda e modificar as condições gerais da liquidez da economia, bem como as atividades das instituições individuais, cujos problemas relacionados a sua instabilidade intrínseca podem afetar e ameaçar a segurança e a estabilidade do sistema em seu conjunto. Definindo o campo de ação, as regras e as normas de conduta que devem ser respeitadas por todas as instituições, o banco central procura circunscrever o 
espaço da concorrência bancária. Mas, tal iniciativa se choca com a lógica de acumulação dos bancos e provoca reações.

Nesse contexto, o principal desafio dos organismos de regulamentação é assegurar que a busca contínua de lucros pelos bancos individuais seja efetuada em condições adequadas, ou seja, sem ameaçar a estabilidade do sistema bancário em seu conjunto - tanto em termos doméstico como internacional. Pela supervisão e fiscalização estrita das normas e de regras continuamente aprimoradas, as autoridades de regulamentação devem procurar prevenir a ocorrência de práticas perigosas de alguns bancos que, impulsionados pela lógica concorrencial, têm a tendência de assumir riscos excessivos.

Todavia, como destaca Minsky (1986, p. 250), esse é um jogo perdido, pois os banqueiros têm muito mais a ganhar do que os burocratas do banco central. Adicionalmente, é sempre possível que os bancos centrais - que, em vários países, supostamente possuem independência ou autonomia política - sejam em realidade instituições dominadas por aqueles que deveriam controlar, isto é, os próprios bancos. A existência de autoridades monetárias ou instituições de regulamentação sob influência e controle do lobby bancário explicaria, pelo menos em parte, o fato de que os bancos não são examinados com rigor, exceto quando é demasiadamente tarde frente às crises que então já eclodiram.

A atividade bancária é, desse modo, marcada por uma tensão permanente entre os objetivos de estabilidade do sistema e a procura de novas e maiores fontes de lucros pelos bancos individuais. Os bancos sempre buscam escapar dos limites fixados pelas autoridades de regulamentação, sobretudo se tais limites o impedem de aproveitar e aumentar as oportunidades de lucro. O sucesso em livrar-se dos limites regulatórios vai estar condicionado pelo ambiente institucional e jurídico no qual atuam. Esse ambiente condiciona também as formas assumidas pela concorrência bancária que se inscreve, assim, nos limites fixados pela regulamentação, cujo objetivo é preservar a convenção monetária e a solidez do sistema bancário. É possível, contudo, que a dinâmica concorrencial contribua para a incoerência crescente do regime monetário e financeiro em vigor, provocando sua modificação.

Há um conflito irreconciliável entre a busca de valorização da riqueza pelos bancos e a natureza de "bem público" da função monetária, ${ }^{10}$ que essas instituições privadas com fins lucrativos empreendem na economia capitalista. Em virtude desse conflito, o espaço e as formas da concorrência apresentam a particularidade de serem essencialmente circunscritas aos limites fixados pela regulamentação, os quais variam de acordo com a estrutura institucional e jurídica

(10) A ideia da moeda como "bem público" foi desenvolvida por Polanyi (1944) que demonstrou que a moeda exige a gestão estatal e não pode ser relegada à autorregulação do mercado. 
existente em cada país. Porém, esses limites não são imutáveis; ao contrário, evoluem com o desenvolvimento da economia, pois os bancos reagem às modificações no ambiente macroeconômico, regulatório e competitivo no qual atuam e, ao mesmo tempo, agem ativamente sobre as transformações que são aí produzidas.

Nos Estados Unidos, por exemplo, ao longo dos anos 1970, para superar as desvantagens impostas pela regulamentação, os bancos procuraram ativamente diversificar suas atividades, criando novos instrumentos e novos mercados. A dinâmica concorrencial real dos bancos e demais instituições financeiras provocou modificações na regulamentação. $O$ chamado processo de desregulamentação realizado nesse país significou uma validação ex post de práticas e atividades formalmente interditadas, mas que efetivamente eram realizadas pelos bancos e seus rivais. As transformações iniciadas nos Estados Unidos se repercutiram em cascata em diversos países, embora com ritmos e intensidades bem diferentes. ${ }^{11}$

Uma das principais características gerais da concorrência capitalista é que, em princípio, um novo concorrente pode chegar a qualquer momento. No caso dos bancos, a regulamentação estabelece as condições precisas para a entrada (e também para a saída) das instituições que exercem a atividade bancária. ${ }^{12}$ As regras sobre as condições de entrada das instituições estrangeiras nos mercados nacionais, mas também sobre a entrada de novos concorrentes domésticos nos mercados locais definem, em geral, o capital mínimo necessário e o perfil do administrador (probidade, experiência etc.).

Igualmente, podem existir regras relativas à expansão intergeográfica dos bancos no território nacional. Tais normas tornam a estrutura do sistema bancário um tanto rígida, favorecendo certas instituições - como era o caso dos pequenos bancos locais americanos que possuíam, até o início dos anos 1990, mercados protegidos pela lei, impedindo a entrada de novos concorrentes potenciais. Nos países onde a legislação não é precisa na definição das atividades tipicamente bancárias, pode acontecer que instituições não submetidas ao controle prudencial aplicado aos bancos possam efetuar atividades próximas, competindo diretamente com esses últimos.

A concorrência entre os bancos e entre estes e as instituições financeiras não-bancárias pode assumir diferentes formas de acordo com as características

(11) Sobre a desregulamentação no sistema financeiro americano, ver, entre outros, Guttmann (1994), Cintra (1997) e Freitas (1997b).

(12) Em geral, a saída dos bancos é resolvida pela intervenção dos bancos centrais como prestamista em última instância. As partes solventes são vendidas a outros bancos, enquanto os créditos irrecuperáveis são absorvidos seja pela agência de seguro de depósito, seja pelo Tesouro, como aconteceu no Brasil na segunda metade dos anos 1990, mediante o Programa de Estímulo à Reestruturação e ao Fortalecimento do Sistema Financeiro Nacional (Proer). 
institucionais e legais da atividade bancária e financeira que prevalecem em diferentes países, em determinados momentos e em circunstâncias específicas. Porém, enquanto processo de luta pela apropriação e valorização da riqueza, ela está sempre presente. Às vezes, em virtude da regulamentação bancária em vigor, que varia de modo considerável nos diferentes sistemas bancários nacionais, as oportunidades que os bancos possuem de criar vantagens competitivas vis-à-vis aos seus rivais são reduzidas, mas isto está longe de significar que a concorrência seja tênue ou ausente. Mesmo se os bancos não forem livres para oferecer um amplo leque de taxas de juros aos seus clientes ou novos produtos e serviços, sempre existe a possibilidade de buscar a diferenciação pela construção de uma imagem de solidez, tradição e expertise, ou mesmo pela obtenção de informações privilegiadas.

Ao contrário, se a regulamentação bancária é pouco precisa, a concorrência pode assumir formas destruidoras, ameaçando a estabilidade do sistema de crédito em seu conjunto. Esse é o caso, por exemplo, de uma expansão excessiva dos empréstimos sem uma avaliação adequada dos riscos envolvidos. A crise das hipotecas subprime nos Estados Unidos e sua posterior transformação em uma crise financeira internacional sistêmica é ilustração clara do potencial destruidor da concorrência em ambiente de regulamentação fluida. A redução acentuada das margens de intermediação pode igualmente debilitar certos bancos e gerar efeitos perturbadores sobre o conjunto do sistema.

Em resumo, pode-se afirmar que a atividade bancária é um negócio lucrativo e dinâmico, no qual os bancos administram seus ativos e passivos de modo a obter vantagens competitivas. Todavia, o espaço da concorrência bancária é circunscrito pela regulamentação, que pretende assegurar que a busca de lucros pelos bancos individuais seja feita nas condições as mais seguras possíveis, sem ameaçar a estabilidade do sistema de pagamento e de crédito. Os bancos, impulsionados pela lógica de valorização, procuram escapar aos controles e ampliar os espaços de ação através da inovação. Existe, assim, uma tensão dinâmica entre o processo competitivo inovador dos bancos (e de outras instituições financeiras) e a necessidade de aperfeiçoamento contínuo da regulamentação, dado que o comportamento dos bancos pode contribuir para o aumento da instabilidade financeira da economia.

Como destaca Minsky (1986), a flexibilidade das finanças necessária ao desenvolvimento da economia não pode existir fora dos procedimentos bancários. Isso torna a atividade bancária e financeira indispensável ao dinamismo do capitalismo. Contudo, a ação dinâmica e inovadora dos bancos pode ser igualmente uma importante força perturbadora, dado que afeta tanto o volume e a distribuição das finanças como o comportamento cíclico dos preços, das rendas e do emprego. 
$\mathrm{Na}$ atividade bancária há um risco que "ultrapassa os limites das ações particulares dos bancos e da autoridade supervisora. Trata-se do 'risco de negócio', proveniente de decisões empresariais que os bancos e as demais instituições financeiras podem influenciar, mas não são capazes de controlar inteiramente" (Almeida; Freitas, 1998, p. 56). Ademais, esse risco pode não ter nenhuma relação com a maior ou menor prudência com que os bancos formam seus portfólios e as autoridades efetuam seus trabalhos de controle e supervisão do sistema bancário. Sem desqualificar os esforços de monitoramento e avaliação, é preciso reconhecer a capacidade limitada - seja dos próprios bancos, seja da regulação e supervisão financeira - em controlar a qualidade dos créditos detidos pelo sistema bancário em face desse tipo de risco e do caráter inerentemente instável da atividade financeira.

Além disso, a própria dinâmica concorrencial na atividade bancária tende a promover uma subestimação dos riscos. Os bancos desempenham um papel central na emergência de estruturas financeiras frágeis e no aprofundamento da instabilidade financeira (Freitas, 1997a). As pressões competitivas e a preocupação com a rentabilidade conduzem os bancos a ampliar suas atividades na fase de expansão da economia, sem considerar a assunção excessiva de risco. Porém, frente às modificações nas condições macroeconômicas, podem retrair abruptamente suas atividades de tal modo que ameaçam sua própria solidez, dado que esta atitude pode conduzir seus devedores à falência.

Para limitar a instabilidade inerente ao sistema bancário, as autoridades procuram impor regras de prudência para o funcionamento dos bancos, que se aplicam sobre a composição e qualidade do crédito e sobre os níveis de endividamento, entre outros. No entanto, com as inovações financeiras, os bancos tentam evitar todo e qualquer controle. Os novos instrumentos e procedimentos contribuem para ampliar a complexidade das estruturas financeiras e das relações entre os devedores e os credores. O resultado é o aumento da instabilidade da economia, como bem mostrou Hyman Minsky em diferentes ocasiões.

Em um contexto de euforia, a dinâmica financeira ganha autonomia em relação ao crescimento. É essa autonomia que conduz à fragilidade financeira, dado que introduz um viés entre os resultados financeiros otimistas e as condições reais da acumulação de capital. A fragilidade crescente não é percebida pelos agentes econômicos, permanecendo dissimulada até que ocorram modificações imprevistas nas condições macroeconômicas. Na situação, os agentes endividados buscam a liquidez através da venda de ativos, enquanto os bancos diminuem a oferta de crédito face à elevação dos riscos (Aglietta, 1995, p. 61).

Logo que os preços dos ativos entram em trajetória de queda, as dúvidas sobre a solvabilidade dos estoques das dívidas passadas podem levar os bancos a 
evitar a concessão de novos créditos. Os bancos, como intermediários, interpõem suas garantias entre os depositantes (credores finais) e os devedores. Mas, a garantia bancária não é boa se o valor monetário dos ativos reais que o devedor oferece, como colateral da operação de crédito, não corresponde ao montante de recursos avançados pelos bancos. Por essa razão, uma diminuição acentuada do valor monetário dos ativos representa uma ameaça à higidez da estrutura financeira da economia em seu conjunto.

Esse movimento de liquidação de ativos e de contração dos créditos implica na queda dos preços dos ativos e também na redução dos lucros, da produção corrente e do emprego. Como mostrou Minsky (1986), não existe nenhum mecanismo automático que garanta a reversão do processo deflacionista. Somente as ações do banco central e do governo podem impedir o agravamento da deflação e a transformação da recessão em depressão.

O envolvimento dos bancos com os sucessivos movimentos especulativos do tipo inflação de ativos (asset price inflation) nos mercados acionários, imobiliários e de derivativos tem estado na origem da eclosão de graves crises financeiras, em vários países desenvolvidos e em desenvolvimento, independentemente das fases do ciclo econômico. A contração do crédito que se segue à explosão das bolhas especulativas afeta, indistintamente, especuladores e empresários - no sentido de Keynes (1936) -, pois sujeitos à preferência pela liquidez, os bancos procuram investir seus fundos diretamente em ativos líquidos e seguros, como os títulos públicos.

O comportamento míope dos bancos, no que se refere aos efeitos da contração de crédito, foi apontado por Keynes (1931, p. 159). E foi com essa visão defeituosa que os bancos se comportaram face ao desastre, várias vezes, nas últimas décadas do século XX e na presente década. São inúmeros os episódios, como a crise da dívida dos países em desenvolvimento no início da década de 1980, o financiamento das transações imobiliárias nos países centrais (Estados Unidos, Japão, Reino Unido e, em menor grau, França) no final dos anos 1980, e a crise asiática no final dos anos 1990. Quanto a esta última, a não-renovação das linhas de crédito bancário desempenhou um papel central na propagação da crise, que teve início na Tailândia em julho de 1997 e rapidamente se espraiou, por efeito de contágio e de regionalização dos riscos, para os demais países da região, atingindo igualmente Rússia, Argentina e Brasil.

Como responsável pela estabilidade do sistema monetário e pelo funcionamento regular do sistema de pagamento, o banco central tem a obrigação de controlar a moeda e o crédito. Como responsável pela estabilidade do sistema de pagamento e crédito, precisa garantir aos bancos toda a liquidez de que necessitam em momentos de graves dificuldades. Há, portanto, uma evidente 
contradição entre essas duas funções que possuem objetivos opostos. Ao atuar como prestamista em última instância em momentos de tensão financeira para impedir a eclosão sistêmica, o banco central precisar deixar de lado suas preocupações com a estabilidade monetária.

Ao longo dos anos 1980, as autoridades governamentais de vários países industrializados adotaram políticas de desregulamentação e liberalização, permitindo a emergência de novos concorrentes nos sistemas financeiros e ampliando o leque de atividades permitidas aos bancos. Inspiradas nas formulações teóricas da economia convencional, tais políticas tinham como propósito explícito introduzir a concorrência, no sentido neoclássico do termo, nos mercados financeiros. ${ }^{13} \mathrm{Na}$ visão do mainstream, a concorrência assegura a alocação ótima dos recursos e dos mercados, uma melhor diversificação de riscos e margens de lucros mais estreitas para as instituições financeiras. A extensão do processo de desregulamentação variou significativamente entre os países. Grosso modo, as principais medidas foram: eliminação dos controles quantitativos de crédito, eliminação dos tetos de taxa de juros dos depósitos, abolição dos limites às atividades das instituições financeiras, em particular a supressão das barreiras institucionais entre os bancos comerciais e de investimento, etc. Contudo, o resultado não se deu conforme o esperado, pois, além de se basearem numa visão simplista do funcionamento real da economia capitalista, tais políticas não levaram em consideração a instabilidade intrínseca da atividade bancária.

Dada a intensificação das pressões competitivas, os bancos passaram a privilegiar as operações mais arriscadas, que oferecem em contrapartida maiores ganhos, contribuindo para o aumento da fragilidade financeira e para a elevação dos riscos de crise sistêmica. Em certos países, a prática do liability management $\mathrm{e}$ o desmantelamento dos sistemas de controle das taxas de juros introduziram a concorrência via preços no sistema bancário, provocando a elevação dos custos de captação dos bancos e a diminuição significativa das margens.

Assim, a consequência da execução de políticas de desregulamentação fundadas em ideias que não reconhecem nem o caráter ambivalente da moeda enquanto "bem" público e "bem" privado, nem o duplo papel dos bancos enquanto participantes ativos do processo de criação monetária e como empresas com fins lucrativos, submetidas à lógica implacável da valorização da riqueza - foi a fragilidade crescente dos sistemas financeiros nacionais e a expansão vertiginosa das atividades especulativas, sustentadas pelo crédito bancário. A adaptação e o fortalecimento das regras prudenciais ocorreram demasiadamente tarde, em certos casos, para evitar a irrupção de graves crises bancárias.

(13) Um balanço exaustivo das políticas de "concorrência" introduzidas pelas autoridades governamentais dos países da OCDE nos anos 1980, com o propósito de melhorar a eficiência dos sistemas financeiros, é traçado por Bröker (1989). 
Paradoxalmente, ao reforçar a dominância do capital financeiro sobre o capital produtivo no capitalismo contemporâneo, a introdução de políticas neoliberais contribuiu para recolocar com força a questão do papel do Estado e de suas políticas de regulamentação monetária e financeira. ${ }^{14}$

Com a globalização financeira e a chamada "ditadura dos mercados", a estabilidade de preços domésticos tornou-se o objetivo primordial dos bancos centrais, seja nos países industrializados, seja nos países em desenvolvimento. Porém, esse objetivo opõe-se à função essencial dos bancos centrais, a saber, a de atuar como prestamista em última instância para impedir a eclosão de crise de confiança no sistema bancário. A teoria econômica convencional passou então a defender a ideia de que o banco central deve procurar assegurar ativamente a regulamentação e a fiscalização das atividades dos bancos, seja só ou em conjunto com outros organismos governamentais criados com esse propósito. A regulamentação prudencial seria, portanto, um excelente meio de prevenir a ocorrência de problemas que exijam a intervenção do banco central como prestamista em última instância e comprometam, assim, o cumprimento das metas de inflação.

Porém, concomitantemente ao surgimento da tese da independência do banco central no âmbito da corrente novo-clássica veio a ideia de criação de um organismo autônomo, com a atribuição específica de regulamentar e controlar o sistema bancário. Desde então, todos os bancos centrais que se tornaram independentes do Poder Executivo - para desempenhar sem qualquer interferência a função de formular e executar a política monetária com o objetivo estatutário exclusivo de zelar pela estabilidade do valor da moeda - deixaram de ser responsáveis pela regulamentação e supervisão bancária. A lógica subjacente nesta transferência de atribuições é que o banco central deve concentrar todos os seus esforços em cumprir as metas de inflação, preocupando-se exclusivamente com a estabilidade dos preços. ${ }^{15}$

Os esforços de aprimoramento das regras e técnicas de regulamentação e supervisão bancárias realizadas no âmbito do Comitê de Supervisão Bancária do BIS, que se consubstanciou na divulgação dos 25 Princípios para uma Supervisão Bancária Efetiva em janeiro de 1997, foram realizados exatamente com o propósito de evitar a assunção de riscos excessivos pelos bancos com atuação

(14) Sobre esse tema, ver: Boyer e Drache (1996) e Chesnais (1996).

(15) Cabe destacar, todavia, que entre os economistas da corrente principal essa transferência da função de regulamentação e supervisão bancária não era consensual. Um dos seus principais opositores é Charles Goodhart (1995), contrário à criação da Financial Supervision Authority (FSA) no Reino Unido. O episódio da corrida bancária ao Northern Rock em setembro de 2007, que resultou em sua nacionalização no início de 2008, mostrou que houve problemas de comunicação entre a FSA e o Banco da Inglaterra, que demorou a atuar como prestamista em última instância, como admitiu seu presidente à BBC News (Peston, 2007). 
internacional e assegurar a estabilidade financeira. Esses princípios, revistos em 2006 para incorporar os novos critérios de avaliação de risco do Acordo de Basileia de 2004 (Basileia II), ${ }^{16}$ fornecem um guia para as autoridades nacionais fiscalizarem se os bancos estão medindo e gerenciando de forma adequada os riscos assumidos e mantendo o capital próprio no nível mínimo requerido.

A crise financeira, originada no mercado americano de hipotecas residenciais para tomadores sem ou com fraco histórico de crédito, denominadas hipotecas subprime, ${ }^{17}$ constitui o exemplo mais recente de como a dinâmica concorrencial bancária impõe desafios à regulamentação e supervisão prudenciais. Embora os grandes bancos internacionais americanos e europeus adotem, desde o final dos anos 1990, procedimentos sofisticados de avaliação dos riscos de crédito e de mercado, esses sistemas de gerenciamento de risco não impediram o forte envolvimento e exposição dessas instituições com a pirâmide de crédito erigida em cima de financiamentos imobiliários a tomadores sem ou com histórico de crédito ruim. Ao contrário, esses sistemas, aliados às complexas técnicas de engenharia financeira, estimularam a criação desenfreada de novos produtos financeiros estruturados durante o boom do mercado imobiliário americano iniciado em 2003.

Com a expansão da concessão de empréstimos imobiliários a tomadores de alto risco, os bancos fizeram uso intenso das transações não-registradas no balanço, transferindo aos SIVs parte de suas carteiras de empréstimos subprime, de modo a evitar os requerimentos de capital associados a esses ativos. Paralelamente, concediam linhas de crédito contingentes para as emissões pelos SIVS de produtos financeiros estruturados que combinam ativos financeiros de natureza e níveis de risco distintos, metamorfoseando-os em ativos classificados com grau de investimento. Emitidos sob a forma de tranches com diferentes classificações de risco, esses ativos financeiros foram vendidos para bancos, fundos de investimento, fundos de hedge e seguradoras, tanto nos Estados Unidos como no exterior (Europa e Ásia), bem como para investidores mais avessos a risco, como os fundos de pensão.

(16) Em 1999, foi iniciada uma ampla revisão do Acordo de 1988, que culminou na aprovação do Acordo de Basileia II em 2004 para entrada em vigor em dezembro de 2007. Esse novo Acordo, bem mais complexo do que o anterior, se apoia em três pilares: 1) coeficiente de capital mínimo de $8 \%$, com a definição de novos critérios de avaliação de risco; 2) métodos de supervisão bancária com revisão contínua; 3) disciplina de mercado, com o fornecimento pelos bancos de informações amplas sob seu gerenciamento de risco e adequação de capital para que seus acionistas, investidores e demais participantes do mercado possam realizar sua própria avaliação de risco. A discussão dos avanços e limites dos Acordos de Basileia foge do objetivo desse artigo. Para uma análise crítica desses Acordos na perspectiva pós-keynesiana, ver, dentre outros, Kregel (2006) e Wray (2006).

(17) Sobre a crise do mercado subprime, ver: Kregel (2007 e 2008). 
Dada a integração dos diferentes segmentos dos mercados, a crise iniciada no mercado hipotecário se espalhou. Igualmente, atravessou fronteiras, afetando instituições financeiras no Canadá, no Reino Unido e na Europa. Em um cenário de forte incerteza em relação ao risco de contraparte, os bancos passaram a exercer preferência pela liquidez, contraindo os empréstimos nos mercados interbancários. Igualmente, reduziram a concessão de crédito aos clientes, mesmo os de excelente risco, contribuindo para a desaceleração das economias, sobretudo a americana, que ainda é o motor da economia mundial.

A contração da liquidez nos mercados interbancários exigiu a pronta intervenção dos bancos centrais, sobretudo do Federal Reserve e do Banco Central Europeu (BCE) que, desde julho de 2007, vem injetando recursos nos mercados monetários. Houve, igualmente, duas ações coordenadas de injeção de liquidez realizada por cinco bancos centrais (Federal Reserve, BCE, Banco da Inglaterra, Swiss National Bank, Bank of Canada), uma em dezembro de 2007 e outra no dia 11 de março de 2008. Embora temporariamente acalmem os mercados, reduzindo as taxas interbancárias, essas ações ainda não tiveram o efeito de conter o aprofundamento da crise, em razão da dimensão da pirâmide de crédito construída em cima dos empréstimos de hipotecas de alto risco e do grau de incerteza quanto à magnitude real das perdas.

A crise atual está longe de seu fim, porém é de se esperar que, em razão da sua magnitude e extensão, resulte na reavaliação dos métodos de supervisão bancária e no reforço da regulamentação prudencial, uma vez que tanto os bancos como as autoridades governamentais confiaram em demasia nos modelos internos de gestão de riscos. Prevendo esses desdobramentos, os grandes bancos internacionais, filiados ao Institute of International Finance, aprovaram no início de março de 2008 um conjunto de medidas de autorregulação, dentre as quais o exame mais acurado do risco dos produtos estruturados. Porém, dada a lógica concorrencial que condiciona as estratégias das instituições bancárias, é impensável relegar aos próprios bancos a tarefa de se autorregular.

\section{Considerações finais}

Neste artigo, procurou-se mostrar, a partir das contribuições de Keynes, de autores pós-keynesianos e autores heterodoxos, o duplo papel que os bancos desempenham na economia capitalista moderna, na qual são os únicos agentes econômicos que combinam criação monetária e gestão do capital de empréstimo. De um lado, criam moeda, sob a forma de depósito à vista, ao conceder crédito. De outro, atuam como intermediários mobilizando a poupança financeira e servindo de elo entre a esfera da circulação produtiva e a esfera da circulação financeira. Estas funções são cruciais na dinâmica da acumulação de capital. 
Maria Cristina Penido de Freitas

Todavia, estes agentes privados - no coração do sistema monetário e de crédito da economia - estão submetidos, como todos os demais agentes econômicos capitalistas, à lógica de valorização da riqueza, expressa e avaliada em termos monetários. Pressionados pela lógica concorrencial, os bancos tendem a conceder crédito sem uma avaliação adequada dos riscos nos momentos de expansão da economia para, em seguida, contrair o crédito de forma abrupta assim que as expectativas se revertem. Agindo desta maneira míope, provocam sua própria fragilidade patrimonial e ameaçam a estabilidade do sistema de pagamentos e de crédito. Este conflito irreconciliável entre a busca pelos bancos da valorização da riqueza e a natureza de bem público da função monetária que executam exige que o espaço da atividade bancária e, por consequência, das suas formas de concorrência, estejam circunscritas nos limites definidos pela regulamentação.

A regulamentação prudencial e o controle do banco central sobre as atividades bancárias não são fáceis. Pode-se afirmar que há sempre fortes tensões entre os objetivos da autoridade monetária, no sentido de preservar a estabilidade do sistema monetário e de pagamentos, e dos bancos, que procuram continuamente novas formas de aumentar seus lucros. Essas instituições tentam sempre escapar dos limites fixados pelas autoridades de regulamentação, sobretudo se esses limites os impedem de ampliar suas oportunidades de lucro. Seu sucesso vai estar condicionado pelo ambiente legal e institucional no qual atuam. Esse ambiente condiciona igualmente as formas de concorrência bancária, cujo espaço é definido pela regulamentação prudencial com o propósito de preservar a convenção monetária e a solidez do sistema bancário.

É possível que a dinâmica do processo concorrencial bancário contribua para a incoerência crescente do regime monetário e financeiro vigente, conduzindo à sua modificação. Em outras palavras, existe, portanto, uma tensão dinâmica e irreconciliável entre o processo concorrencial inovador dos bancos e a necessidade contínua de aperfeiçoamento da regulamentação, dado que o comportamento dos bancos em busca de valorização contínua pode contribuir para o aumento da instabilidade constitutiva da economia capitalista.

\section{Referências bibliográficas}

AGLIETTA, Michel. Macroéconomie financière. Paris: Editions La Découverte, 1995.

ALMEIDA, Júlio S. G. de; FREITAS, M. Cristina P. A regulamentação do sistema financeiro. Campinas: Unicamp. IE, 1998. (Texto para Discussão, n. 62).

BOYER, Robert; DRACHE, Daniel (Ed.). States against markets: the limits of globalization. London: Routledge, 1996.

BRÖKER, G. Competition in banking. Paris: OECD, 1989. 
CARVALHO, Fernando Cardim. Inovação financeira e regulamentação prudencial: da regulação de liquidez aos Acordos de Basileia. In: SOBREIRA, Rogério (Org.). Regulação financeira e bancária. São Paulo: Editora Atlas, 2005. p. 121-139.

Sobre a centralidade da teoria da preferência pela liquidez na macroeconomia pós-keynesiana. Ensaios FEE, Porto Alegre, v. 17, n. 2, p. 42-77, 1996.

Sobre a endogenia da moeda: réplica ao professor Nogueira da Costa. Revista de Economia Política, São Paulo, v. 13, n. 4, p. 114-121, jul./set. 1993.

Moeda, produção e acumulação: uma perspectiva pós-keynesiana. In: SILVA, Maria Luiza F. da (Org.). Moeda e produção: teorias comparadas. Brasília: Universidade de Brasília, 1992. p. 163-191.

Fundamentos da escola pós-keynesiana. In: AMADEO, Edward (Org.). Ensaios sobre economia política moderna: teoria e história do pensamento econômico. São Paulo: Editora Marco Zero, 1989. p. 179-194.

CHESNAIS, François (Coord.). La mondialisation financière: genèse, coût et enjeux. Paris: Syros, 1996.

CHICK, Victoria. On money, method and Keynes: selected essays. London: St. Martin Press, 1992.

. The evolution of the banking system and the theory of monetary policy. London: University College London, 1988. Mimeografado.

The evolution of the banking system and the theory of saving, investment and interest. Economies et Sociétés, Grenoble, p. 111-1126, Août/Sept. 1986. (Série Monnaie et Production, n. 3).

CINTRA, Marcos A. M. As transformações na estrutura do sistema financeiro dos Estados Unidos: a montagem de um novo regime monetário-financeiro (1980-1995). Tese (Doutorado em Economia)-Instituto de Economia, Universidade Estadual de Campinas, Campinas, 1997.

DAVIDSON, Paul. Money and real world. London: MacMillan, 1978.

DOW, Sheila. Money and the economic process. Aldershot: Edward Elgar Publishing Company, 1993.

Blackwell, 1985.

Macroeconomic thought: a methodological approach. Oxford: Basil

FREITAS, M. Cristina P. de. A evolução dos bancos centrais e seus desafios no contexto da globalização financeira. Estudos Econômicos, São Paulo: Fipe-USP, v. 30, n. 3, p. 397417, jul./set. 2000.

A natureza particular da concorrência bancária e seus efeitos sobre a estabilidade financeira. Economia e Sociedade, Campinas, Unicamp, Instituto de Economia, n. 8, p. 51-83, jun. 1997.

- Concurrence bancaire, spéculation et instabilité financière: une lecture hétérodoxe de l'évolution récente du système financier international. Thèse (Doctorat en Sciences Economiques)-Villetaneuse, Université de Paris 13, 1997. 
Maria Cristina Penido de Freitas

GOODHART, Charles E. (Ed.). The Central banking and financial system. London: Macmillan, 1995.

GUTTMANN, Robert. How credit-money shapes the economy: the United States in a global economy. Armonk: M.E. Sharpe, 1994.

KALDOR, Nicholas. Speculation and economic stability. In: KALDOR, Nicholas. Essays on economic stability and growth. London: Gerald Duckworth \& Co. Ltd., 1960. (Publicado originalmente em 1939).

KEYNES, John M. The general theory of employment, interest and money. London: Macmillan. Royal Economic Society, 1973. (The Collected Writings of John Maynard Keynes, vol. VII). (Publicado originalmente em 1936).

. A monetary theory of production. In: MOGGRIDGE (Ed.). The general theory and after (part I Preparation). London: Macmillan, Royal Economic Society, 1974. (The Collected Writings of John Maynard Keynes, vol. XIII). (Publicado originalmente em 1933).

The distinction between a co-operative economy and an entrepreneur economy. In: MOGGRIDGE (Ed.). The general theory and after (A supplement). London: Macmillan, Royal Economic Society, 1979. (The Collected Writings of John Maynard Keynes, vol. XXIX), (Publicado originalmente em 1933).

The consequences to the banks of the collapse of money value. In: KEYNES, John M.. Essays in persuasion. London: Macmillan/Royal Economic Society (The Collected Writings of John Maynard Keynes, vol. IX), 1973. (Publicado originalmente em 1931).

Treatise on money. London: Macmillan/Royal Economic Society, 1971. (The Collected Writings of John Maynard Keynes, vol. V \& VI) (Publicado originalmente em 1930).

KREGEL, Jan. Minsky's cushions of safety: Systemic risk and the crisis in the U.S. subprime mortgage market. Public Policy Brief, The Levy Economics Institute of Bard College, n. 93, Jan. 2008. Disponível em: http://www.levy.edu.

. The natural instability of financial markets. The Levy Economic Institute of Bard College, Dec. 2007. (Working Paper, n. 523). Disponível em: http://www.levy.org.

. O novo Acordo de Basileia pode ser bem-sucedido naquilo que o Acordo original fracassou. In: MENDONÇA, Ana Rosa R. de; ANDRADE, Rogério P. (Org.). Regulação bancária e dinâmica financeira: evolução e perspectivas a partir dos Acordos de Basileia. Campinas: CERI-IE-Unicamp, 2006. p. 25-37.

MINSKY, Hyman. Stabilizing an unstable economy. New Haven: Yale University Press, 1986.

Financial innovation and financial instability: observations and theory. In:

THE FEDERAL Reserve Bank of St. Louis. Financial innovations: their impact on monetary policy and financial markets. Boston: Kluwer-Mighoff, 1984. p. 21-41.

Can 'it' happen again? Essays on instability and finance. Armok, New York:

M.E. Sharp, 1982. 
NIGGLE, Christopher. The evolution of money, financial institutions and monetary economics. Journal of Economic Issues, v. XXIC, n. 2, p. 443-450, Jun. 1990.

PESTON, Robert. Transcript of interview with Mervyn King, the Governor of the Bank of England. BBC Business, 6 nov. 2007. Disponível em: http://news.bbc.co.uk.

POLANYI, Karl. A grande transformação. Rio de Janeiro: Editora Campus, 1980. (Tradução brasileira do original em inglês publicado em 1944).

STUDART, Rogério. Financial repression and economic development: toward a post Keynesian alternative. Review of Political Economy, v. 5, n. 3, p. 277-298, Jul., 1993.

TOBIN, James. Commercial banking as creators of money. In: TOBIN, James. Essays on Economics, 1982. v. 1. (Publicado originalmente em 1963).

WRAY, L. Randall. Basileia II e a estabilidade financeira: uma abordagem minskyana. In: MENDONÇA, Ana Rosa R. de; ANDRADE, Rogério P. (Org.). Regulação bancária e dinâmica financeira: evolução e perspectivas a partir dos Acordos de Basileia. Campinas: CERI-IE-Unicamp, 2006. p. 145-175. 